\title{
Is there a 'new ethics of abortion'?
}

Raanan Gillon Imperial College, London

\begin{abstract}
This paper argues that the central issue in the abortion debate has not changed since 1967 when the English parliament enacted the Abortion Act. That central issue concerns the moral status of the human fetus. The debate here is not, it is argued, primarily a moral debate, but rather a metaphysical debate andlor a theological debate — though one with massive moral implications. It concerns the nature and attributes that an entity requires to have "full moral standing" or "moral inviolability" including a "right to life". It concerns the question when, in its development from newly fertilised ovum to unequivocally mature, autonomous morally inviolable person does a human being acquire that nature and those attributes, and thus a "right to life". The paper briefly reviews standard answers to these questions, outlining some problems associated with each. Finally there is a brief discussion of one way in which the abortion debate has changed since 1967-notably in the increasingly vociferous claim, especially from disability rights sectors, that abortion on grounds of fetal abnormality implies contempt for and rejection of disabled people - a claim that is rebutted.

(Fournal of Medical Ethics 2001;27 supp1 II:ii5-ii9)
\end{abstract}

Keywords: Abortion; moral status of fetus; abortion of abnormal fetuses

Killing another person if that person is a nonaggressor is regarded as a morally terrible action in most moral communities, which have major moral and legal prohibitions and sanctions against such killing. Far fewer moral communities have similar attitudes and prohibitions against killing all living beings and most cultures are willing to kill some living beings for food and for use of their skins and for other benefits such as the advancement of medicine. But what of the human being as it develops from newly fertilised ovum, to pre-embryo, embryo, fetus, new born baby, to unequivocally mature autonomous person with full moral standing including a moral and legal right not to be killed at least if he or she is not an aggressor? When and on what basis during that development does the unequivocally living human being acquire the moral status of a living human person, here used simply as a shorthand for a human being of full moral status (of the sort all readers of this paper uncontroversially ascribe to each other) including a right to life, again here used as a convenient shorthand for the right not to be killed if not an aggressor. Conversely, when, if at all, and why, is it morally justified to kill ("abort") the developing human being? The answers to these questions are not primarily moral answers, though of course they have major moral implications. Overwhelmingly moral communities do not doubt that to kill a person, at least if he or she is not an aggressor, is, as stated above, a morally terrible action. They agree that people should be protected against such killing by acceptance by all moral agents that every person has a moral and legal right to life. What they disagree about is the scope of that obligation-just what sorts of entities are persons in this sense, and why? Conversely what sorts of attributes manifested by any entity would/should ensure that it is acknowledged to be a person and have full moral standing including a right to life? These are primarily metaphysical and/or theological issues rather than directly moral issues, and people of moral integrity can and do come to carefully thought out but widely different conclusions without in any way undermining that moral integrity, without in any way being "wicked" -or stupid- points that those who are inclined to impugn the morality or intelligence of those who oppose them on this issue should bear in mind and take to heart!

A variety of standard positions have emerged over the centuries. At one end of the spectrum is the fundamentalist stance that claims either that the newly fertilised human ovum is a human person from the moment of conception, or at least that it must be treated as such even if we cannot know precisely when in its subsequent development it becomes "ensouled"-roughly speaking the theological equivalent of becoming a "person" as defined above. The latter position is the position of the contemporary Roman Catholic Church as expressed in its 1974 Declaration on Abortion by the Roman Congregation for the Doctrine of Faith ${ }^{1}$ and is shared by some other faith communities. A little further on from the "moment of conception" stance is the 14 days stance, developed by the Warnock Commission in the UK when it was considering in vitro fertilisation. ${ }^{2}$ Here development of the "primitive streak", at 14 days, was determined to be the cut off point after which research on, followed by destruction of, human embryos was to be prohibited-a cut off point subsequently enshrined in the Human Fertilisation and Embryology Act, 1990. Although the Warnock commission produced little justification for its choice of 14 days, this was subsequently defended in depth by the Roman Catholic philosopher Norman Ford, who argued that the primitive streak stage marked the true formation of a new living individual with a human nature. ${ }^{3}$ This occurs after a two-week developmental process that follows fertilisation, within 
what he dubbed the "proembryo" and what Mary Warnock called the "pre-embryo".

Interestingly St Thomas Aquinas, one of the greatest philosophers of the Roman Catholic faith proposed (following, as he often did, an Aristotelian lead) that ensoulment or "hominisation" did not occur until 40 days for boys and 90 days for girls.

A traditional distinction has been that of "quickening"-the time at which the pregnant woman can feel her fetus move inside her (generally around 20-21 weeks in a first pregnancy, often several weeks earlier in subsequent pregnancies) undoubtedly a time of great emotional significance for the pregnant woman.

Moving along the developmental spectrum, "brain life" (the development of a functioning brain), ${ }^{5}$ and the development of the ability to have experiences, including sensory experiences (sentience $)^{6}$ have also been proposed as criteria for differentiating the "fully fledged" human person with full moral status from the developing human being that lacks a right to life. Estimates of the onset of a capacity for sentience vary but 20-24 weeks are commonly proposed.

A technological criterion favoured among many doctors working in neonatology and also in gynaecology is the concept of viability - the stage of fetal development at which the fetus can survive independently of the pregnant woman, given suitable intensive care. ${ }^{7}$ This seems to be a steadily reducing period but is currently around 20-22 weeks.

The legal criterion in most jurisdictions is birth, ${ }^{8}$ when the human fetus becomes a legal person, and certainly this corresponds with an enormous psychological change in all involved with the newborn baby-here it is, a new human being joining the human community.

Finally some argue that even at birth a baby is not yet a person, that a necessary attribute for being a person is a capacity to be aware of oneself, and or a capacity to value oneself, or even-in Kantian mode - a capacity for autonomous thinking, and that these capacities develop some time-at least some months - after birth. ${ }^{9}$ And to round off this thumbnail sketch some argue that a necessary condition for full moral status as a human person is social acceptance as such, and that therefore without such social acceptance a human being of any stage of development does not have the full moral status and rights of a person.

Perhaps the most intellectually robust of these criteria are those at each end of the spectrum, ie the criterion of conception, and the criterion of a capacity for self awareness-but all these criteria have associated problems, and it has always seemed important to me for all of us involved in the abortion issue to be clear what our own positions are and how we respond to the problems and objections associated with our position, whatever it may be. Not much has changed in that respect either since the introduction of the Abortion Act in 1967.
Full moral status from conception or soon afterwards

First the standard Roman Catholic "moment of conception" stance-which for reasons of space I shall here assimilate to the official Roman Catholic stance that while we cannot know when ensoulment or hominisation occurs, we must behave as though it occurred at conception so as to prevent the dreadful sin of killing an innocent ensouled human being or human person. There are two main problems with this position - as with the Ford's unorthodox Roman Catholic view that the human person begins at 14 days: first why should we believe that a single cell or a clump of cells is a person, with the same level of moral importance as we readily acknowledge each other to have? Second are we prepared to accept the implications of this stance for medical practice-for example that we should refuse to permit not just all abortions and all in vitro research on human embryos but also even postcoital contraception, since this works in part by preventing a newly fertilised ovum from implanting into the lining of the uterus?

Now sometimes the first objection is met by the argument from potential. There are two versions of this. The first is what might be dubbed the ordinary language version. According to this version, of course the newly fertilised ovum and early embryo does not have the attributes of a person-it can't think or reflect or imagine or experience, or do things for itself. But it has the potential do all those things, it has in short the potential to become the wonderful being that we fully fledged human beings are. It should therefore be valued and respected for that potential and be accorded the same moral status and protection that we accord each other. The problems with this version of the argument from potential is that we don't normally, let alone necessarily, accord the same value to $\mathrm{x}$ which has the potential to be y as we accord to y itself. An acorn has the potential to be an oak tree but not many buyers would pay the same for acorns as they would pay for oak trees. A caterpillar has the potential to become a butterfly but few nature lovers would accord the same value to caterpillars as to the butterflies they might become. Moreover as John Harris has pointed out we all of us have the potential to be corpses-but this in no way justifies treating or valuing each other as though we already were corpses. Moreover, as he also points out, if potential to be fully fledged human people was sufficient to require being valued as if that potential had already been realised then a sperm and an egg considered together also have that potential; and, given techniques of cloning that led to Dolly the sheep, so do many ordinary cells of the human body. Are they all to be accorded a right to life?

The second version of the argument from potential avoids such problems but only by asserting the conclusion it seeks to derive. According to the second version, the newly fertilised ovum is "a human being or person with potential, not a potential human person". ${ }^{10}$ According to this version of the argument from potential the newly fertilised ovum 
and thus the early embryo just is a person from fertilisation; even though its attributes as a person are not yet obvious they are all present in the genetic and organisational structure of the new human being, and left alone to develop, they will gradually emerge. While the subject bears extensive debate and sophisticated analysis, few who are not already committed to a theological requirement that a new human person begins either at fertilisation or else very soon afterwards - for example Ford's 14 days stance $^{3}$ - are persuaded by either version of the argument from potential which is seen either as begging the question by asserting the disputed conclusion as a premise in version two, or as totally implausible special pleading in version one. Many who reject the argument from potential will none the less agree that the potential to become something of great value-for example a human person-undoubtedly belongs to human embryos and fetuses and this gives them at least a prima facie value, and in many cases, where the pregnant woman herself longs to have a new baby, makes them extremely important. But they will be unpersuaded that this potential necessarily imparts the same value-let alone the same intrinsic value - to all human embryos and fetuses.

Aquinas's 40 days for boys and 90 days for girls may be quickly passed over, as may the suggestion that quickening - the feeling of fetal movement by the pregnant woman -is relevant to the moral status of the fetus. In passing it is of note however that Roman Catholic thinking has by no means been univocal, either now or in the past, that ensoulment occurs at fertilisation, and that it is important to differentiate between psychological feelings that are of undoubted importance for the pregnant woman, or indeed for others, and plausible criteria for determining the intrinsic moral status of the embryo and fetus.

\section{Brain life and the capacity for sentience}

What about the fetus's development of a brain, and along with that its development of a capacity for sentience - a capacity to have experiences including sensory experiences, whether of touch or pain or of sound? Are these plausible criteria for the "personhood" or moral inviolability of the human fetus? There seems little doubt that it is because of our brains that we humans have special attributes to which we attach special moral value - of which the most important one is widely accepted to be our capacity to be autonomous - to think reflectively for ourselves, or what amounts to much the same thing, to have "free will". Moreover at the end of our lives it is now widely accepted that it is the death of our brains that is the fundamental determinant of our deaths and of the cessation at any rate of our legal personhood. Should therefore the corresponding onset of "brain life" be the determinant of the start of our moral and/or our legal personhood? And should the capacity for having experiences and especially sensory experiences constitute the operational evidence of the onset of such "brain life"? Some anti-abortion activists have made much of evidence that at a late stage of pregnancy fetuses respond to stimuli in ways that indicate that they are sentient, and for my own part this seems quite likely - after all there's not much doubt (these days) that a newborn baby is sentientcapable of feeling pain and of other experiences; it seems highly implausible that this capacity is in some way switched on by the process of birth and far more likely that it is already present at some stage in utero. The question still remains, is sentience of the human fetus a plausible criterion for personhood-for fetal "moral inviolability", including a fetal right to life?

A major problem for such an assumption is that if the capacity of sentience is sufficient for personhood and a right to life in human fetuses why should it not equally be sufficient for personhood and a right to life in all other living beings, including all the vertebrates that we currently are ready to kill for their meat and skins and uses in medical research? Of course many animal rights supporters would not see this as a problem at all-but merely as confirmation that our current moral and legal attitudes to animals are grievously mistaken and "speciesist". They would agree with Jeremy Bentham, one of the founding fathers of utilitarianism, that all animals who can experience pain and suffering, pleasure and happiness are of equal moral concern and that the proper expression of that moral concern is to minimise suffering and pain and maximise pleasure and happiness, whether animal or human. Without some additional premises making a special case for humans, those who would make the capacity for sentience a sufficient criterion for fetal personhood seem logically committed to a similar position, as are those who would accept as such a criterion the existence of a fetal brain with the capacity for sentience. One practical moral conclusion is important to note. If sentience is not accepted as the criterion for full moral status, and abortion continues to be permitted after the stage at which the fetus has developed the capacity to feel pain, then it seems morally important to ensure that the fetus is not caused pain by the procedure itself-so for late abortions some form of anaesthetic or other means of preventing fetal pain should be part of the abortion operation.

Viability is the criterion favoured by many who work in the field of neonatology, and also by some gynaecologists who accept abortion but who also believe that at some stage in their development fetuses acquire a right to life after which they should not be aborted. There is a crucial practical as well as intuitive dividing line, such doctors often feel, between those fetuses who, given intensive care are capable of continuing their survival and development outside the uterus, and those who are not viable in this sense and it is this viability, they believe, that affords a criterion for distinguishing between those fetuses that do and do not have a right to life.

The main problem with the viability criterion is that it is entirely dependent on our technological 
skills. If what we are looking for is some characteristic(s) of the developing human being itself, in which to ground its intrinsic moral status, then the skills and technologies of others are hardly likely to suffice; yet viability is a criterion that depends almost entirely on the technological skills of others. Even these days there will be an enormous difference between fetal viability in a Third World village and in a First World neonatal intensive care unit. Moreover given the exponential development of human technological inventiveness-wizardry some might call it-Aldous Huxley's Brave New World possibilities of growing human embryos and fetuses entirely outside the human body could become reality-in which case the criterion of viability will have collapsed into the criterion of fertilisation.

So does the legal criterion - birth - get us out of our difficulties? Legally speaking the answer is largely yes - for UK law, like that of many other jurisdictions, is explicit that a fetus is not legally speaking a person and does not have the legal rights of persons including the right to life enjoyed by (natural) persons, whereas a born child is a person and does have a right to life. While in practica terms the simple criterion of birth is generally easy to apply and corresponds to a stage when what was previously hidden and private inside another human being is now a revealed, public, and clearly separate social entity, as a criterion for moral differentiation of a human being's intrinsic moral status it seems highly implausible. Essentially it is a criterion of what might be dubbed biological geography, asserting that a human being does not have a right to life if it lies north of a vaginal introitus but has a right to life once it has passed south and has (entirely) emerged from the vagina. What morally relevant changes can there have been in the fetus in its passage from inside to outside its mother's body to underpin such a momentous change in its intrinsic moral status?

\section{Self awareness}

Finally, criteria that require not just a capacity for awarenesss, experience or sentience as a necessary condition for being a person with full moral status, but that require a capacity for self awareness as a criterion for personhood. Such approaches are usually grounded in the notion that what is remarkable and of special moral importance about human beings is their ability to reflect rationally, to be aware of their moral natures and their responsibilities to others and to themselves, and to be able to make autonomous decisions based on such reflection, to be agents who have free will. Following the lead of the 17th century physicianphilosopher John Locke, a capacity for self awareness is regarded as at least a necessary condition by those, including myself, who accept this approach to the attributes needed to be a person On this basis a newborn child is not a person, for neonates do not have such capacities; and therefore on this basis newborn babies would not have any intrinsic right to life stemming from their natures.
This fact alone is so counterintuitive-even horrifying to some-that for many it affords a reductio ad absurdum - any argument that leads to a conclusion that newborn babies are not people and do not have a right to life must be flawed and should in any case be rejected for leading to such absurd conclusions. While such a summary way with arguments that lead to conclusions that seem absurd or at least highly counterintuitive may feel satisfying, it does not dispose of the arguments. Nor does it dispose of a widespread intuition that in the case of very severely handicapped newborn babies parents and doctors who agree that it would be better if the infant did not survive and live a life of severe handicap should be permitted, morally and legally, to allow them to die, even in cases where medical and nursing intervention could be expected to save them, and even in cases where they would not permit similar latitude of choice on behalf of an older handicapped child or adult.

\section{Abortion for abnormality an affront to disabled people?}

It should be clear therefore that any substantive position on when a new human being should be considered to be a human person-a human being with full moral standing including a right to life and thus a right not to be killed at least if not an aggressor-has associated problems. This has not changed since these issues were debated in the 1960 s. What has changed, however, is the debate about abortion on grounds of fetal abnormality, one of the least controversial clauses at the time David Steel's Abortion Bill was being debated. These days an increasingly forceful disability rights movement is arguing that abortion on the grounds of fetal abnormality is morally and legally objectionable in discriminating against disabled people and in manifesting and encouraging disrespect, hostility and contempt for disabled people. In this last section of the paper I shall give the gist of my rebuttal of this argument. First, of course, it is important to be clear that the argument is logically watertight if it is agreed that human fetuses (and embryos) are people, and thus that fetuses and embryos with disabling abnormalities are disabled people. If that is the starting position then of course the argument is impeccable, and to abort-that is, to kill-fetuses on the grounds that they have abnormalities that are disabling is as morally repugnant as it would be to kill adults who have disabling abnormalities. It would indeed manifest and encourage disrespect, hostility, and contempt for disabled people.

But are those of us who justify abortion for sufficient benefit and who therefore must reject the claim that fetuses are people or persons with full moral status including a right to life, to be found guilty of such discimination if we justify abortion on the grounds of fetal abnormality? The answer is unequivocally no!

Instead what we seek to justify is availability of choice to pregnant women to prevent the creation of disabled people by aborting fetuses with 
abnormalities that would disable the people they would become-if they were allowed to develop into people. If the response to this argument is that such fetuses already have a right to life, disabled or not, then the response is, as noted above, logically impeccable but begs the question about the moral status of the fetus by asserting that it has full moral standing. If that assertion were accepted then, as noted above, it is as morally wrong to kill a disabled fetus as to kill a disabled child or adult, and as wrong to abort a normal fetus as it would be to kill a normal child or adult.

If, however, the fetus is held not to have full moral status and not to have a right to life, then aborting an abnormal fetus shows no more disrespect or hostility to disabled people than aborting a normal fetus shows disrespect or hostility to people who don't have disabilities. It shows no more disrespect to people than deciding not to become pregnant at all shows disrespect to people. To permit people to have abortions in order to allow them to choose not to bring a disabled person into being in no way justifies, let alone does it entail, any undermining of our obligations to look after and care for, respect and be fair to the disabled people who do exist. If embryos and fetuses are not yet people or persons - if they do not yet have full moral status including a right to life, then there is simply no logical connection between making abortion available to prevent the creation of a disabled person and discriminating adversely against disabled people.
Raanan Gillon is Emeritus Professor of Medical Ethics at Imperial College, London and Senior National Health Service Partner, Imperial College Medical Partnership. From 1981-2001 he was Editor of the fournal of Medical Ethics.

\section{References and notes}

1 As reported in Mahoney J. Bioethics and belief. London: Sheed and Ward, 1984: 67.

2 Department of Social Security. Report of the committee of inquiry into human fertilisation and embryology [chair, Lady Mary Warnock]. London: HMSO, 1984: 58-66.

3 Ford N. When did I begin? Cambridge: Cambridge University Press, 1988 (throughout but especially 164-82)

4 See reference 1: 58 and reference 3: 28 and 41 .

5 Goldenring J. The brain life theory: towards a consistent biological definition of humanness. Fournal of Medical Ethics 1985;11:198-204 (for a critique of the putative symmetry between brain death and brain life see Jones D. Brain birth and personal identity. Fournal of Medical Ethics 1989;15:173-8)

6 The originator of the "sentience criterion" was probably Jeremy Bentham in his Introduction to the principles of morals and legislation, ch 17. Two contemporary exponents are Peter Singer in his Animal liberation. Wellingborough: Thorsons, Singer in his Animal liberation. Wellingborough: Thorsons, especially chs 1 and 6; and Sumner L. Abortion and moral ch 4 .

7 See for example Strong C, Anderson G. The moral status of the near term fetus. Fournal of Medical Ethics 1989;15:23-7.

8 A useful discussion of English law in this area is in Davies M. Textbook on medical law. London: Blackstone Press, 1996: 23759.

9 See for example Tooley M. Abortion and infanticide. Oxford: Clarendon Press, 1983 especially 40-104. And Harris J. The value of life. London: Routledge and Kegan Paul, 1985 especially 7-27.

10 For this formulation see for example reference 3: 82 and 111. 